\title{
A $100 \%$ waste-based alkali-activated material by using olive-stone biomass ash (OBA) and blast furnace slag (BFS)
}

\author{
A. Font ${ }^{a}$, L. Soriano ${ }^{a}$, J.C.B. Moraes ${ }^{b}$, M.M. Tashima ${ }^{b}$, J. Monzó ${ }^{a}$, M.V. Borrachero ${ }^{a}$, J. Payáa, \\ a ICITECH - GIQUIMA Instituto de Ciencia y Tecnología del Hormigón, Universitat Politècnica de Valencia, Valencia, Spain \\ ${ }^{\mathrm{b}}$ UNESP - Grupo de Pesquisa MAC - Materiais Alternativos de Construção, Universidade Estadual Paulista (UNESP), Faculdade de Engenharia, Ilha Solteira, São Paulo, Brazil
}

\section{A R T I C L E I N F O}

\section{Article history:}

Received 14 February 2017

Received in revised form 3 April 2017

Accepted 25 May 2017

Available online 30 May 2017

\section{Keywords:}

Biomass ash

Thermal analysis

Alkali-activated material

Ceramics

\begin{abstract}
A B S T R A C T
This study presents the use of olive-stone biomass ash (OBA) as an alkali source in alkali-activated materials (AAM) based on blast furnace slag (BFS). The OBA was physically and chemically characterized. It presented high $\mathrm{K}_{2} \mathrm{O}$ and $\mathrm{CaO}$ contents, and yielded high alkalinity in water medium. The newly designed $\mathrm{OBA}+\mathrm{BFS}$ mixes (a $100 \%$ waste-based AAM) reached a compressive strength of $30 \mathrm{MPa}$ after 7 days of curing at $65^{\circ} \mathrm{C}$, which was higher than for BFS activated with $\mathrm{KOH}$ solution. Thermogravimetric studies showed the formation of $\mathrm{C}-\mathrm{S}-\mathrm{H} /(\mathrm{C}, \mathrm{K})-\mathrm{A}-\mathrm{S}-\mathrm{H}$ gels and hydrotalcite. The OBA presented excellent performance as a component in AAM and a good valorisation was achieved.
\end{abstract}

(c) 2017 Elsevier B.V. All rights reserved.

\section{Introduction}

Alkali-activated materials (AAM) are prepared by mixing a solid precursor and an alkaline solution (usually sodium or potassium hydroxides, carbonates or silicates). The precursor is an aluminosilicate-based mineral material and in many cases this is a waste from industrial activity (e.g. fly ash, blast furnace slag, ceramic wastes). Environmental benefits are provided by the use of AAMs, compared to Portland cement, due to their low associated carbon footprint [1]. Alternative binder solutions also have been reported by the use of mixtures of wastes, in which one of the components has a biomass waste origin: sugarcane straw ash has been successfully tested in $50 / 50 \%$ wt mixtures with blast furnace slag [2] with a significant reduction in the sodium silicate content. However, the alkaline solutions are prepared by means of the use of synthetic chemical reagents, with relatively high costs in economic and environmental terms. The use of alkaline wastes could help to solve this issue. In some cases, part of chemical reagent has been successfully replaced by a waste (e.g. rice husk ash replaced silicate source in [3]).

In this way, some alkaline ashes can be obtained by power generation from biomass combustion. After this process, a solid byproduct is generated, the biomass ash. Vassilev et al. [4] have classified these biomass ashes into four types, depending on the oxides compositions: S, K, C and CK types.

\footnotetext{
* Corresponding author.

E-mail address: jjpaya@cst.upv.es (J. Payá).
}

The challenge of finding a use for these biomass ashes needs to be addressed. Greener concrete has been developed by the use of different ashes from farming waste residues [5]. Alternatively, alkali-rich ashes could be used for preparing activation solutions for AAM.

This paper presents an investigation of a waste obtained after the combustion of olive stone: olive-stone biomass ash (OBA) The residue is rich in $\mathrm{K}_{2} \mathrm{O}$ and $\mathrm{CaO}$ ( $\mathrm{CK}$ ash according to [4]). Olive biomass ash has already been studied in cement blends with interesting results. In these studies, the use of olive cake, pulp and stone in the combustion process produced an ash with high $\mathrm{SiO}_{2}$ content [6,7]. Peys et al. [8] studied the use of some potassium-rich biomass ashes as an activator in metakaolin mixtures, where they obtained a maximum compressive strength of $40 \mathrm{MPa}$ after 28 days of curing.

The aim of this research is to present the potential use of olivestone biomass ash (OBA) as an alkali source in AAMs based on blast furnace slag (BFS). The OBA was fully characterized and it was used in AAM. The OBA/BFS blend was compared to water activated BFS and $\mathrm{KOH}$ activated BFS to assess the effectiveness of OBA in the matrix development.

\section{Experimental}

\subsection{Materials}

Blast furnace slag (BFS) was supplied by Cementval (Valencia, Spain) (see Composition in Table 1) with a mean particle diameter 
Table 1

Chemical composition (wt\%) of OBA and BFS.

\begin{tabular}{|c|c|c|c|c|c|c|c|c|c|c|c|}
\hline & $\mathrm{SiO}_{2}$ & $\mathrm{Al}_{2} \mathrm{O}_{3}$ & $\mathrm{Fe}_{2} \mathrm{O}_{3}$ & $\mathrm{CaO}$ & $\mathrm{K}_{2} \mathrm{O}$ & MgO & $\mathrm{P}_{2} \mathrm{O}_{5}$ & $\mathrm{SO}_{3}$ & $\mathrm{Na}_{2} \mathrm{O}$ & Others & LOI $^{*}$ \\
\hline OBA & 5.33 & 0.70 & 3.45 & 27.77 & 32.16 & 5.13 & 2.68 & 1.67 & 0.78 & 0.95 & 18.90 \\
\hline BFS & 30.53 & 10.55 & 1.29 & 40.15 & 0.57 & 7.43 & 0.26 & 1.93 & 0.87 & 0.89 & 5.53 \\
\hline
\end{tabular}

Loss on ignition.

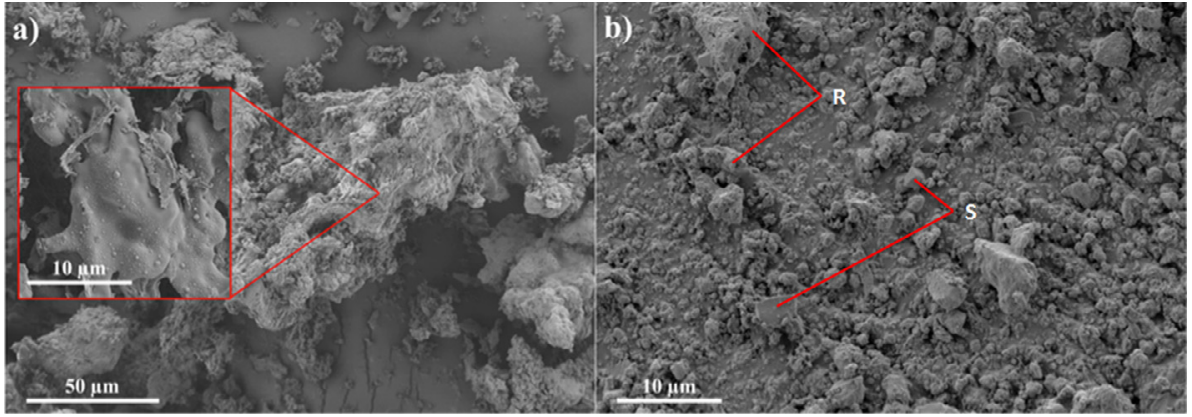

Fig. 1. FESEM micrographs of: (a) original OBA; (b) OBA after the milling process (R: rough surface; S: smooth surface).

of $26.0 \mu \mathrm{m}$. Olive-stone biomass ash (OBA) was supplied by Almazara Candela (Elche, Spain). The original ash was milled for $20 \mathrm{~min}$ in a ball mill in order to homogenise the sample and to reduce the particle diameter. Commercial potassium hydroxide $(\mathrm{KOH})$ was used (Panreac-SA, 85\% purity).

\subsection{Methods}

The OBA was characterized by X-ray fluorescence (XRF), $\mathrm{pH}$ in deionized water, particle size distribution (PSD), X-ray diffraction (XRD) and field emission scanning electron microscopy (FESEM). XRF was carried out using a Philips Magix Pro XRF instrument. The $\mathrm{pH}$ measurement was carried out by means of a Crison micro PH2001 pH meter, and the PSD was measured by means of a Malvern Instruments Mastersizer 2000. XRD was carried out by a Bruker AXS D8 Advance. FESEM micrographs were taken by an ULTRA 55-ZEISS with the sample covered by carbon.

Three different mixes were designed in this study by using BFS as precursor, where the activating solution was: a) still water without any alkali source (M1); b) an aqueous solution of $\mathrm{KOH}$ to produce an alkali-activated material (M2); or c) the mixture of OBA and water in a 0.47 ratio (M3). The $\mathrm{K}^{+}$molarity selected in this study was $4 \mathrm{M}$ for the M2. For M3, the same molarity was calculated as for the $\mathrm{M} 2$ based on the $\mathrm{K}_{2} \mathrm{O}$ content in the OBA: $18.8 \%$ of OBA was added with respect to the BFS. Water:BFS and BFS:sand (for mortars) ratios were maintained as constant values of 0.40 and $1: 3$ by mass, respectively. Samples were cured at $65{ }^{\circ} \mathrm{C}$ and $100 \%$ relative humidity. Mortars were assessed by their compressive strength (universal testing machine). Thermogravimetric analyses (TGA) of the pastes were performed using a TGA850 Mettler Toledo thermobalance (temperature range: $35-500^{\circ} \mathrm{C}$; heating rate: $10^{\circ}-$ $\mathrm{C} \cdot \mathrm{min}^{-1}$ in an $\mathrm{N}_{2}$ atmosphere. Samples were tested after 3 and 7 days.

\section{Results and discussion}

\subsection{Chemical and physical characterization of $O B A$}

The chemical composition of OBA is summarized in Table 1. The main oxides of the ash are $\mathrm{K}_{2} \mathrm{O}(32.16 \%)$ and $\mathrm{CaO}$ (27.77\%), both significantly higher than previously reported [6]. The sum of over $60 \%$ of these oxides suggests that OBA can be an important alkali

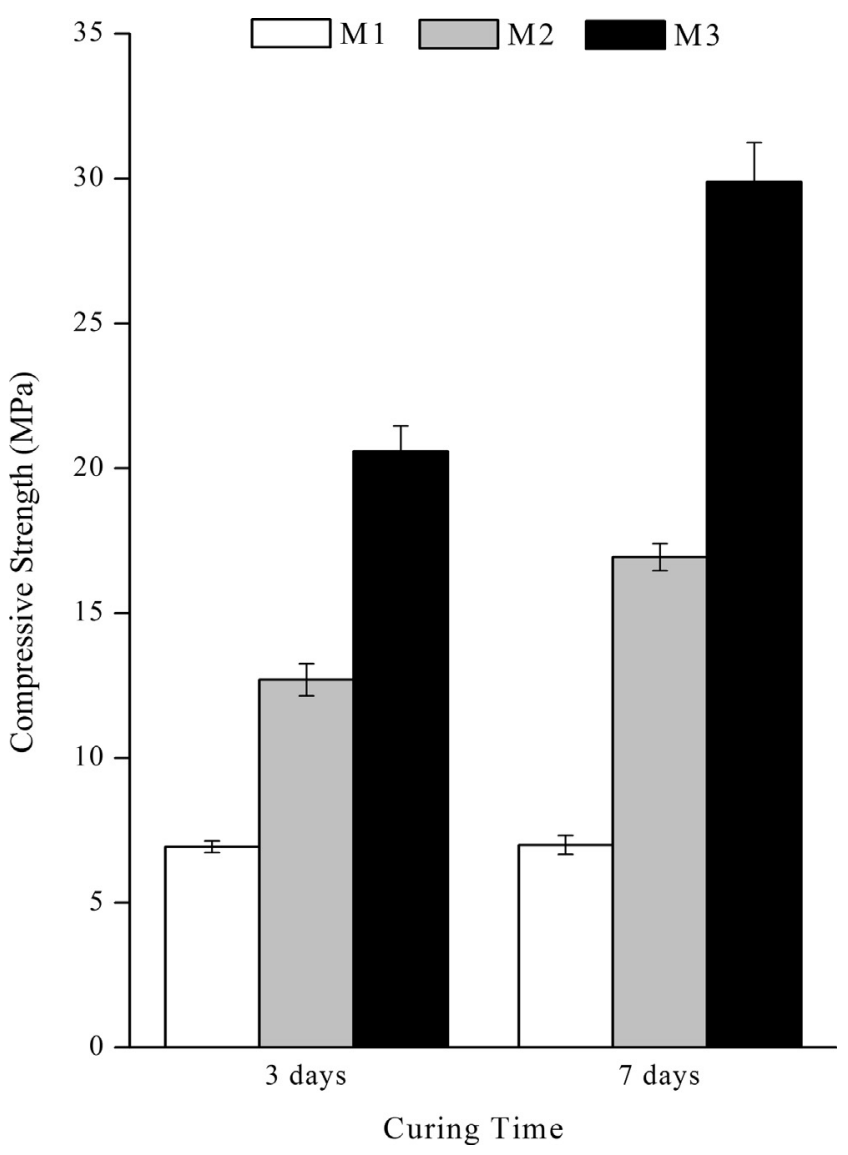

Fig. 2. Compressive strength of mortars M1, M2 and M3 after 3 and 7 days of curing time at $65^{\circ} \mathrm{C}$.

source in AAMs. The OBA showed high alkalinity in water suspension with a value equal to 13.5 for an OBA:water ratio of 0.47 . The mean particle diameter and 90\%-passing diameter $\left(\mathrm{d}_{90}\right)$ values were 20.1 and $45.2 \mu \mathrm{m}$, respectively. XRD studies showed that the main crystalline phases are: portlandite $\left(\mathrm{Ca}(\mathrm{OH})_{2}\right)$, calcite $\left(\mathrm{CaCO}_{3}\right)$, anorthite $\left(\mathrm{CaAl}_{2} \mathrm{Si}_{2} \mathrm{O}_{8}\right)$ and kalicinite $\left(\mathrm{KHCO}_{3}\right)$. FESEM images are shown in Fig. 1. Fig. 1a presents the OBA before the 


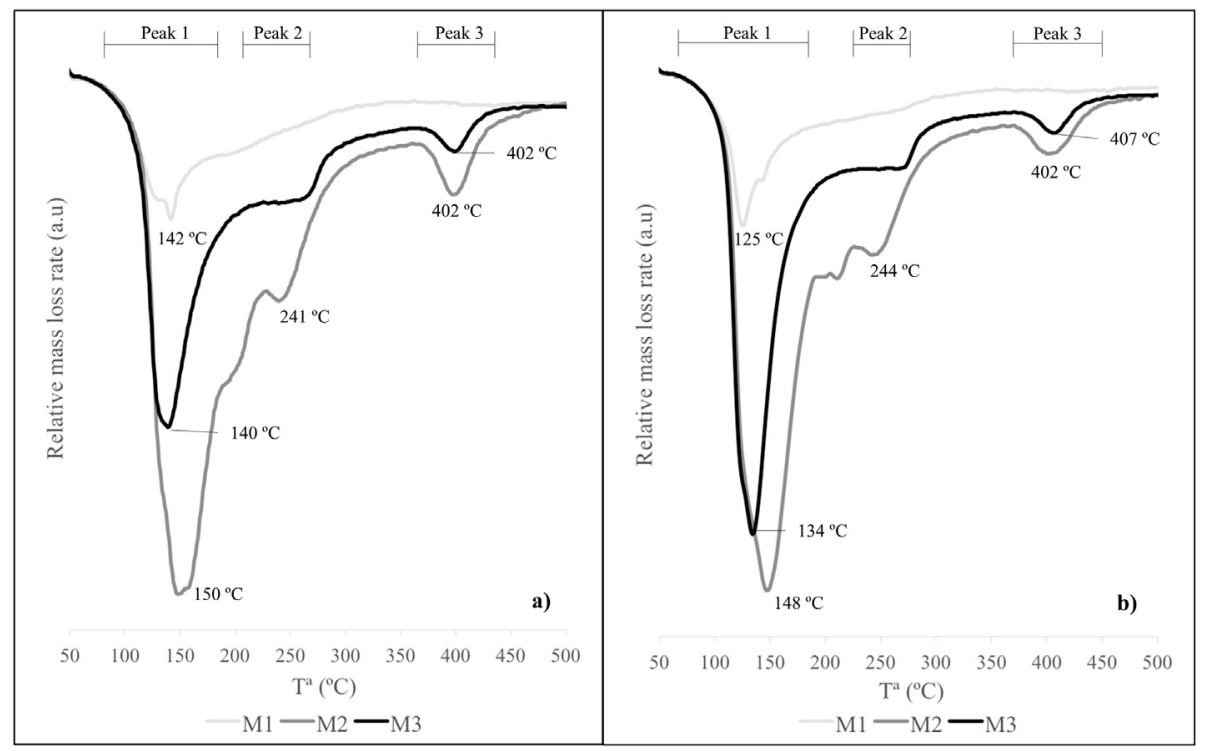

Fig. 3. DTG curves from pastes M1, M2 and M3 after: (a) 3 days; (b) 7 days of curing.

milling process. At a lower magnification, highly irregular particles with size larger than $100 \mu \mathrm{m}$ can be observed. When these particles are observed at a higher magnification, they appear to have a rough surface with signs of a sinterization event. Fig. $1 \mathrm{~b}$ shows the OBA after the milling process. The particle size significantly reduced when compared to the original, and a more homogeneous particle distribution was observed, showing rough and smooth particle surfaces.

\subsection{Characterization of mortars and pastes}

The compressive strength for M1, M2 and M3 mortars after 3 and 7 curing days is shown in Fig. 2. It is noticeable that for the M3 mixture, the system is 100\% waste-based material. After 3 days of curing, the compressive strength for the control mortar with only water (M1) was $6.9 \mathrm{MPa}$, which corresponds to the selfhydraulic properties of the BFS [9]. This value was significantly lower than those obtained for the other two mortars: M2 and M3 presented $12.7 \mathrm{MPa}$ and $20.6 \mathrm{MPa}$, respectively. On the one hand, these results show that the alkaline activation of BFS improved the mechanical development when compared to a system with only water, as expected. On the other hand, the presence of OBA in the mixture enabled it to reach a compressive strength higher than that obtained in $\mathrm{KOH}$ alkali-activated mortar. Probably, the presence of both calcium and potassium from the OBA influenced positively the activation of BFS. Regarding 7-days cured mortars, M1 effectively maintained its compressive strength at 3 days, reaching 7.0 MPa. M2 and M3 showed a strength gain: the former mortar reached $16.9 \mathrm{MPa}$ (33\% gain with respect to the 3 days sample) and the latter presented $29.9 \mathrm{MPa}$ (45\% gain). It can be noticed that the presence of the OBA not only yielded the highest compressive strength, but also showed the best improvement in this curing interval.

Thermogravimetric analyses (DTG curves) for the M1, M2 and M3 pastes after 3 and 7 days of curing are shown in Fig. 3. In this test, three main peaks could be observed: similar results were reported by Rivera et al. [10] for BFS activated by potassium hydroxide/silicate mixture. Peak 1 is related to dehydration of C$\mathrm{S}-\mathrm{H}$ gel (the main peak in all pastes). Peak 2 is associated with dehydration of C-A-S-H and (C,K)-A-S-H gels from the activated products. Peak 3 is only observed for the M2 and M3 pastes, and is related to the dehydration of the hydrotalcite [11] (confirmed by XRD). No important difference between the DTG peaks for 3 and 7 days for all pastes was observed. Regarding the relative mass losses in the interval of $35-500{ }^{\circ} \mathrm{C}$, after 3 days of curing the M2 paste presented the highest value (12.92\%), followed by M3 (8.35\%) and M1 (4.07\%). The mass losses (a measure of the chemically combined water) showed significant increases from 3 to 7 days of curing because of the progress of the reaction. The corresponding mass losses for 7 days of curing were $\mathrm{M} 2=15.51 \%$, M3 $=10.82 \%$ and $\mathrm{M} 1=4.52 \%$. This behaviour can be attributed to the formation of more cementing compounds from the reaction process. Curiously, the combined water for M2 is higher than that for M3, although the strength is opposite. This behaviour may be due to two facts: on the one hand, the presence of more solid in the M3 mix (18.8\% more) achieves a filler effect in the activated matrix. On the other hand, the presence of both potassium and calcium probably modifies the nature of the hydrates, making a stronger matrix.

\section{Conclusions}

OBA showed a high amount of calcium and potassium in its composition. In water suspension, OBA produces an alkaline medium. When the OBA was reacted with BFS, the ash influenced positively the compressive strength development of the mortars. After 3 and 7 days of curing time at $65^{\circ} \mathrm{C}$, this OBA + BFS mix showed better strength than the corresponding $\mathrm{KOH}$-activated system, suggesting a synergic process in terms of the filler effect and chemical effect. The use of OBA opens an interesting new line in the preparation of $100 \%$-waste based AAMs. These results showed that new and better ecological and economical materials have been designed.

\section{Acknowledgements}

Thanks are given to Almazara Candela for providing the OBA sample and BIOMASA project (UPV).

\section{References}

[1] L.K. Turner, F.G. Collins, Carbon dioxide equivalent $\left(\mathrm{CO}_{2}-\mathrm{e}\right)$ emissions: a comparison between geopolymer and OPC cement concrete, Constr. Build. Mater. 43 (2013) 125-130.

[2] J.C.B. Moraes, M.M. Tashima, J.L. Akasaki, J.L.P. Melges, J. Monzó, M.V. Borrachero, L. Soriano, J. Payá, Increasing the sustainability of alkali- 
activated binders: the use of sugar cane straw ash (SCSA), Constr. Build. Mater. 124 (2016) 148-154.

[3] N. Bouzón, J. Payá, M.V. Borrachero, L. Soriano, M.M. Tashima, J. Monzó Refluxed rice husk ash/NaOH suspension for preparing alkali activated binders, Mater. Lett. 115 (2014) 72-74.

[4] S.V. Vassilev, D. Baxter, L.K. Andersen, C.G. Vassileva, An overview of the chemical composition of biomass, Fuel 89 (2010) 913-933.

[5] K.H. Mo, U.J. Alengaram, M.Z. Jumaat, S.P. Yap, S.C. Lee, Green concrete partially comprised of farming waste residues: a review, J. Clean. Prod. 117 (2016) 122 138.

[6] M. Cruz-Yusta, I. Mármol, J. Morales, L. Sánchez, Use of olive biomass fly ash in the preparation of environmentally friendly mortars, ACS Environ. Sci. Technol. 45 (2011) 6991-6996.

[7] M. Cabrera, A.P. Galvin, F. Agrela, M.D. Carvajal, J. Ayuso, Characterisation and technical feasibility of using biomass bottom ash for civil infrastructures, Constr. Build. Mater. 58 (2014) 231-244.
[8] A. Peys, H. Rahier, Y. Pontikes, Potassium-rich biomass ashes as activator in metakaolin-based inorganic polymers, Appl. Clay Sci. 119 (2016) 401-416.

[9] S.C. Pal, A. Mukherjee, S.R. Pathak, Investigation of hydraulic activity of ground granulated blast furnace slag in concrete, Cem. Concr. Res. 33 (2003) 14811486.

[10] O.G. Rivera, W.R. Long, C.A. Weiss Jr., R.D. Moser, B.A. Williams, K. TorresCancel, E.R. Gore, P.G. Allison, Effect of elevated temperature on alkaliactivated geopolymeric binders compared to Portland cement-based binders, Cem. Concr. Res. 90 (2016) 43-51.

[11] H.A. Abdel-Gawwad, S. Abd-el-Aleem, Effect of reactive magnesium oxide on properties of alkali activated slag geopolymer cement pastes, Ceramics Silikáty 59 (2015) 37-47. 